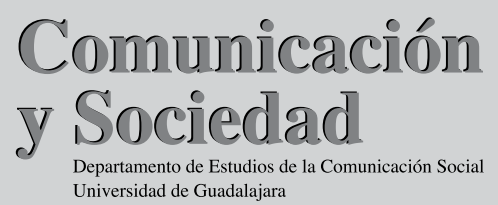

\title{
Latinoamericanos en el sur de Brasil: recepción mediática y ciudadanía de las migraciones transnacionales
}

DENISE COGO 1

LILIANE DUTRA BRIGNOL ${ }^{2}$

En el presente artículo abordamos los procesos de interacción mediática de las migraciones contemporáneas de latinoamericanos en el contexto de la ciudad de Porto Alegre, capital del estado de Rio Grande do Sul, Brasil. Desde la perspectiva de los estudios de recepción latinoamericanos y a través del empleo de historias de vida y de grupos de discusión, analizamos cómo esas interacciones se constituyen en lugares de (re)invención de apropiaciones y usos mediáticos de migrantes que (re)configuran sus experiencias migratorias en ámbito local y conforman procesos identitarios específicos relacionados con la "latinoamericanidad".

PALABRAS CLAVE: medios de comunicación, migraciones, recepción, ciudadanía.
This article discusses the processes of mediatic interaction of contemporary migrations of latin americans in the context of the city of Porto Alegre, Brazil. It is based on the results of an empirical research (between 20042007). Research techniques included 'life history' and 'focal groups', while the theoretical background included several previous studies of reception in Latin America. Discussion focus on how those interactions constitute places of (re)invention of modalities of appropriation and interactive communicative use for migrants, who (re)configure their migratory experiences on a local scope and conform related specific identity processes to the notion of "Latino-Americanidad".

KEY WORDS: communications media; migrations; reception; citizenship.

1 Universidad do Vale do Rio dos Sinos, Brasil.

Correo electrónico: denisecogo@uol.com.br

2 Universidad do Vale do Rio dos Sinos, Brasil.

Correo electrónico: lbrignol@terra.com.br 


\section{INTRODUCCIÓN}

El artículo discute los resultados de una investigación realizada entre 2004 y 20073 sobre las interacciones mediáticas de migrantes latinoamericanos en la ciudad de Porto Alegre, región sur de Brasil. Buscamos entender, por un lado, cómo esas interacciones se constituyen en lugares de (re)invención de modalidades de apropiaciones y usos mediáticos de migrantes latinoamericanos que (re)configuran la dinámica de sus experiencias migratorias en ámbito local, así como conforman procesos identitarios específicos relacionados con la "latinoamericanidad". Por otro lado, buscamos comprender cómo esas interacciones pueden colaborar con la construcción de la ciudadanía, en los ámbitos individual y colectivo, de las migraciones transnacionales en Brasil. ${ }^{4}$

La metodología de la investigación, de carácter cualitativo, combinó la realización de 30 historias de vida con migrantes latinoamericanos de 11 nacionalidades, complementada con dos grupos de discusión donde participaron siete de los 30 migrantes. Como procedimiento metodológico complementario, la investigación incluyó la colecta y observación de noticias sobre las migraciones contemporáneas publicadas por medios de comunicación impresos y televisivos nacionales, locales y en medios comunitarios producidos por organizaciones de apoyo a las migraciones situadas en Brasil.

3 Investigación empírica realizada por el grupo de investigación Medios de Comunicación y Multiculturalismo, del Programa de Postgrado en Ciencias de la Comunicación de la Universidade do Vale do Rio dos Sinos (Unisinos, Brasil).

4 La investigación fue apoyada con beca de productividad en investigación concedida a la coautora de este trabajo, Denise Cogo, por el Consejo Nacional de Desarrollo Científico y Tecnológico (CNPq), con beca de investigadora asociada concedida por la Unisinos a la coautora del trabajo, Liliane Dutra Brignol, y con becas de iniciación científica concedidas por CNPq, Fapergs y Unisinos a los estudiantes Cristina Wulfhorst (Fapergs), Daiana Ruff da Silva (PIBIC-CNPq), Daiani Barth (UNIBIC-Unisinos), Moreno Cruz Osório (Fapergs) y Ursula Schilling (CNPq). 


\section{ITINERARIO TEÓRICO-METODOLÓGICO}

DE LA INVESTIGACIÓN

\section{Marco teórico y conceptual}

Para el análisis de las relaciones entre migraciones y medios de comunicación, nos filiamos a la perspectiva interaccionista de los estudios de recepción latinoamericanos por posibilitarnos entender los procesos comunicacionales y mediáticos en el marco de la cultura y del cotidiano (Huertas Bailén, 2002; Martín Barbero, 1985; Orozco Gómez, 1987). Dos posicionamientos o modos de abordaje, ambos inspirados en la vertiente teórica de los estudios culturales, demarcan el desarrollo de las investigaciones de recepción en América Latina: 1) las investigaciones que buscan estudiar la recepción a partir de procesos socioculturales y comunicacionales en que no están necesariamente implicados los medios de comunicación, y 2) las investigaciones dirigidas al análisis de la recepción de los medios de comunicación o las prácticas de recepción mediática (Cogo, 2008). 5

Desde esta segunda perspectiva, la recepción es asumida, en nuestra investigación con los migrantes latinoamericanos, como instancia de interacción con los medios de comunicación a través de la capacidad de los receptores de interpretar los contenidos y otorgar sentidos plurales a las ofertas mediáticas, además de atribuir usos específicos a los medios en su cotidiano. Lo que no implica suponer una impermeabilidad de los receptores frente a la incidencia de los medios de comunicación, pues reconocemos los límites de su autonomía en el ejercicio de esas interpretaciones y usos mediáticos, sobre todo si consideramos los procesos unidireccionales y asimétricos que demarcan el espacio de la comunicación masiva.

A esa perspectiva dirigida a distinguir los sentidos y usos mediáticos de los migrantes latinoamericanos, agregamos el interés específico de examinar cómo, en el marco de esas interacciones con los medios

5 Esos dos posicionamientos son vistos en términos de énfasis asumidos en las investigaciones latinoamericanas de recepción, no pudiendo, sin embargo, ser disociados, por entender que en los procesos mediáticos siempre está implicada una dimensión comunicacional. 
de comunicación, se construyen prácticas y acciones específicas para la ciudadanía de las migraciones transnacionales en la actualidad. Es lo que definimos como un "ir más allá del mapeo de los usos de medios" para identificar, entre los migrantes latinoamericanos, posibilidades de conformación de micropolíticas del sujeto que se originan en sus interacciones cotidianas con los medios de comunicación.

De esas interacciones de los migrantes latinoamericanos con los medios de comunicación pueden, por lo tanto, estar originándose experiencias de comunicación ciudadana que se definen por el ejercicio de participación pública en procesos comunicativos, en relación no sólo con el Estado, sino con todas las demás instituciones y grupos sociales. ${ }^{6}$ Ciudadanía que, a partir de la interrelación migraciones y comunicación, no consiste solamente en un espacio objetivo, de carácter jurídico o institucional, sino que también es una instancia subjetiva y vivida, relacionada con el movimiento y la acción (Mezzadra, 2005).

Para profundizar en las experiencias concretas de recepción mediática de las migraciones latinoamericanas en el contexto de Porto Alegre, reconocemos, aun, que la heterogeneidad de las experiencias migratorias transnacionales ya no nos permite asociarlas a motivaciones puramente económicas, sino definirlas como proyectos que involucran múltiples subjetividades (de orden cultural, política, económica, etc.). Además, las migraciones dejaron de constituirse exclusivamente como movimientos de permanencia que asumen un punto de partida y llegada o espacialidades fijas y temporalidades estables, $o$ incluso portan deseos comunes de integración a los espacios de tránsito y migración. ${ }^{7}$ No desconsideramos, con esto, las causas "objetivas" y circunstancias materiales, así como los procesos de dominación y desigualdades que están implicados en las dinámicas de traslados e hibridaciones culturales que resultan del ejercicio de la subjetividad

6 En torno de esa perspectiva nos valemos de la formulación de Mata (2006:515) sobre ciudadanía comunicativa.

7 Por esto nuestra opción, en la investigación, por el uso de la terminología "migrante" y no "inmigrante" por permitir evidenciar, de modo más apropiado, esos trazos de diversidad de los movimientos migratorios contemporáneos a escala transnacional. 
de los migrantes. O sea, no postulamos absolutamente un simple y libre cruzar nómade de fronteras, culturas e identidades como definidor de los movimientos migratorios (ibidem: 47). Apenas reivindicamos un modo plural de comprender las experiencias migratorias que se torne útil para explicar las prácticas comunicativas y mediáticas de las migraciones desde una perspectiva de la especificidad que asumen las relaciones entre comunicación, cultura y ciudadanía en el contexto de los estudios de recepción mediática en América Latina. La subjetividad informa cómo las migraciones actuales pasan a definirse por su capacidad de portar y sintetizar una pluralidad de posiciones, vínculos, relaciones, conflictos y disputas sociopolíticas, económicas y culturales en las sociedades contemporáneas.

Los propios relatos de los migrantes latinoamericanos entrevistados en Porto Alegre nos posibilitaron percibir los distintos deseos que se combinan para movilizar y posicionar sujetos nacidos en diferentes contextos nacionales en el emprendimiento de proyectos migratorios. Constatamos que una pluralidad de modos de concretar y vivenciar esos proyectos colaboran para conformar dinámicas singulares de experimentación de medios de comunicación por parte de los migrantes, dinámicas que aparecen relacionadas con las negociaciones y procesos de integración culturales. Algunas de esas dinámicas aluden al migrante como sujeto que se agrega a otros migrantes y no migrantes y moviliza capacidades de solidaridad para transformar los medios de comunicación en lugar de (re)creación de experiencias identitarias individuales y colectivas. Esa comprensión de las interacciones de carácter individual y colectivo de los migrantes es conducida, en este artículo, con relación a la construcción de sus experiencias identitarias de "latinoamericanidad", entendidas no como una esencia, sino como una tarea inconclusa que involucra procesos de hibridación y heterogeneidad cultural (García Canclini, 2002).

Proceso metodológico: contextualización y constitución de la muestra De un total de 510 mil extranjeros residentes en Brasil, 130 mil son oriundos de la región de América Latina y el Caribe, según datos del censo demográfico del año 2000 del IBGE (Instituto Brasileño de Geografía y Estadística), situando al país como el cuarto receptor de mi- 
gración intrarregional. Paraguayos, argentinos, uruguayos y bolivianos son las cuatro nacionalidades de latinoamericanos mayoritariamente presentes en el contexto brasileño (Avila, 2007). ${ }^{8}$

En el caso específico del estado de Rio Grande do Sul, de un total de 39,249 extranjeros, 23,833 proceden de 18 países latinoamericanos, especialmente Uruguay $(16,637)$, Argentina $(4,447)$, Chile $(773)$ y Paraguay (738). Según estos indicadores, $40.7 \%$ de los migrantes que llegan al estado se establecen en la capital Porto Alegre, que concentra la mayoría de los extranjeros de otros países, incluyendo los latinos. ${ }^{9}$

Pero, ¿cómo localizar empíricamente, en el contexto del sur de Brasil, experiencias migratorias relacionadas con la latinoamericanidad? A partir de esta pregunta iniciamos nuestra investigación con el objetivo de definir la muestra formada por 30 migrantes procedentes de 11 países de América Latina residentes en Porto Alegre. En este proceso nos deparamos, en el ámbito local, con lo que viene siendo definido como dos de los principales trazos constitutivos de las migraciones transnacionales: la tensión de la (in)visibilidad de esas migraciones en el escenario local y, al mismo tiempo, la realidad plural que las configuran. Esos trazos aparecen vinculados al propio protagonismo social de las tecnologías de la comunicación que actúan en la construcción y visibilidad pública de imágenes de las migraciones transnacionales, asociándolas frecuentemente a la violencia, conflicto y criminalidad. ${ }^{10}$ Esas tecnologías ejercen, también, un papel en el

8 Los extranjeros representan un total de $0.5 \%$ del total de 171 millones y 300 mil brasileños registrados por el censo de población realizado en Brasil en el año 2000.

9 Asumimos que esos indicadores son limitados, revelando tendencias sobre la presencia de migrantes de diferentes nacionalidades en Brasil y en Porto Alegre, pero dejan de registrar las experiencias de clandestinidad o incluso de transitoriedad y fluidez que caracterizan a las migraciones transnacionales en el contexto brasileño.

10 En España tenemos como ejemplo reciente de un imaginario que criminaliza las migraciones, la reiteración mediática de imágenes de la llegada "clandestina" de migrantes africanos en pequeñas embarcaciones denominadas pateras o cayucos. En Brasil podemos remitir a la cobertura dada por los 
reordenamiento del tiempo y del espacio, contribuyendo al incremento y a la pluralización transnacional de las prácticas simbólicas de ejercicio de las identidades culturales de los migrantes, más allá de las localizaciones geográficas.

Porto Alegre, una de las principales puertas brasileñas de entrada al Mercosur, capital del estado brasileño fronterizo, Rio Grande do Sul, que mantiene un conjunto de relaciones históricas de naturaleza económica, sociopolítica, cultural, con países como Argentina y Uruguay, es el escenario de nuestra investigación. La ciudad, con una población de 1' 415,237 habitantes, ${ }^{11}$ es portadora de una fase urbana multicultural que, en cierta medida, contribuye para la dilución de la diferencia y de la alteridad, basadas en trazos fenotípicos que resultan del proceso de mestizaje constitutivo de la sociedad brasileña. Lo que favorece dinámicas de identidades específicas relacionadas con la diversidad cultural de los extranjeros que escogen la ciudad como destino migratorio. ${ }^{12}$

Las mezclas culturales que derivan de las herencias de descendientes de italianos, alemanes, portugueses, polacos, españoles, mayoritarias en la constitución de Rio Grande do Sul, se asocian a otros cruzamientos simbólicos relacionados con la presencia de poblaciones afrobrasileñas e indígenas, observadas especialmente en el área metropolitana de la capital, Porto Alegre. En el marco de esas dinámicas culturales, migrantes oriundos de países latinoamericanos, especialmente del MERCOSUR, no son fácilmente distinguidos en el espacio urbano, a no ser debido al uso del idioma español o del portuñol (mezcla de portugués y español).

medios de masa a incidentes involucrando la "ilegalidad" o criminalidad de brasileños en el exterior.

11 Porto Alegre contaba, en el 2000, con una población total de 1'360,590, según datos del Censo Demográfico del Instituto Brasileño de Geografía y Estadística (IBGE). El censo de 2006, publicado después del cierre de la investigación, registra una población de 1'415,237 habitantes. Ver http://www.ibge.gov. br/cidadesat/topwindow.htm?1. Consultado: 6 de junio de 2007.

12 Cruzando la frontera de Rio Grande do Sul con esos dos países, o, incluso, oriundos de países como Chile y Perú, muchos migrantes llegan a Porto Alegre por vía terrestre. 
Si comparamos, incluso, con lo que observamos en muchas capitales europeas, los migrantes latinoamericanos establecidos en Porto Alegre raramente constituyen guetos espaciales o geográficos, caracterizándose, al contrario, por la dispersión y, muchas veces, transitoriedad, fluidez y fragmentación.

Desde el punto de vista de las culturas latinoamericanas, esos perfiles plurales de la realidad migratoria local sirvieron igualmente para desestabilizar, entre el equipo de investigadores, algunos de los imaginarios sociales $^{13}$ que marcan nuestras relaciones históricas con diferentes naciones de América Latina y del MERCOSUR. Como, por ejemplo, la identificación de Uruguay como la "Suiza de América" y la "europeidad" asociada a los argentinos o chilenos. Esos imaginarios permitieron relativizar y actualizar los perfiles de los flujos migratorios dirigidos al sur del Brasil, que estuvieron anteriormente impulsados por motivaciones políticas, como las relacionadas con dictaduras del Cono Sur. Es lo que pudimos experimentar cuando reparamos, por ejemplo, en latinoamericanos procedentes de esos países instalados en locales muchas veces precarios, situados en barrios de difícil acceso en la periferia de la capital, viviendo de trabajos temporales y experimentando diferentes situaciones de clandestinidad.

Como uno de los espacios estratégicos de apoyo a las migraciones y de encuentro entre los migrantes en Porto Alegre, el CIBAI-Migraciones (Centro Ítalo-Brasileño de Apoyo a las Migraciones), ${ }^{14}$ favoreció nuestra aproximación empírica inicial, con lo que evidenciábamos la invisi-

13 La comprensión de imaginario social nos remite a cuestiones relacionadas al carácter construido de la realidad social, así como a la interpretación que hacen los actores del mundo en que viven y los sentidos que otorgan a sus prácticas sociales. Como patrimonio de grupos de personas, los imaginarios sociales generan, entre sus participantes, un sentimiento de legitimidad ampliamente compartido. Agregamos a esta reflexión el dato de que los medios de comunicación se constituyen, en la actualidad, como una de las principales instancias a protagonizar y ofrecer aportes a la construcción de esos imaginarios (Taylor, 2006; Girola, 2007).

14 El CIBAI-Migraciones mantiene su sede en una iglesia del centro de Porto Alegre, lo que facilita la aproximación y contacto con los migrantes que llegan y/o se establecen en la ciudad. 
bilidad de las migraciones contemporáneas en la región metropolitana de la capital. Los estudios formales y otros registros diarios mantenidos por el CIBAI-Migraciones nos proporcionaron referencias sobre la presencia de migrantes latinoamericanos en Porto Alegre que complementaron las obtenidas por el censo demográfico, y contribuyeron para la composición de la muestra y el contacto con futuros entrevistados. Posteriormente, las propias redes de migrantes se constituyeron en fuentes valiosas para la localización de nuevos entrevistados, minimizando el riesgo de privilegiar apenas las experiencias migratorias que asumen un carácter organizativo por estar, por ejemplo, vinculadas al CIBAIMigraciones.

Las informaciones levantadas en esas incursiones iniciales colaboraron para la constitución de una muestra cualitativa compuesta por 30 migrantes latinoamericanos escogidos a partir del cruzamiento de siete variables: 1) nacionalidad, 2) tiempo de permanencia en Porto Alegre, 3) edad, 4) género (sexo), 5) condición de ciudadanía, 6) vínculos y/o participación en redes y organizaciones de migrantes en nivel local, nacional y/o internacional, 7) experiencias de participación y gestión en medios de comunicación masivos y/o comunitarios.

En la perspectiva de la historia oral como método biográfico, optamos por las historias de vida para recoger las experiencias de interacciones comunicacionales y mediáticas de los migrantes latinoamericanos. El guión de las historias de vida se centró en torno a dos ejes de abordaje, propuestos de modo abierto a los entrevistados: trayectoria de vida y de migración, y trayectoria mediática relacionada con los proyectos migratorios. En el ámbito de los dos ejes, fueron contemplados aspectos específicos relacionados con la identificación personal y el cotidiano de los entrevistados; trayectoria y experiencias de migración; contactos y vínculos con el país de origen; procesos de integración sociocultural en las sociedades brasileña y gaucha; 15 pertenencias identititarias; vínculos con grupos, asociaciones y organizaciones de migrantes o de apoyo a las migraciones; pautas de consumo mediático; procesos de participación y

15 Gaucho es el término utilizado comúnmente para referir a los brasileños nacidos en el estado de Rio Grande do Sul y a sus referentes culturales y locales (por ejemplo, cultura gaucha, clima gaucho, gastronomía gaucha, etc.). 
gestión en el ámbito de los medios de comunicación, y visiones de mundo sobre la construcción de las migraciones en los medios.

Las historias de vida fueron complementadas con la realización de dos grupos de discusión con la participación de un total de siete migrantes latinoamericanos y con la exhibición de tres producciones audiovisuales sobre migraciones latinoamericanas. Un primer grupo fue dinamizado con la exhibición de una edición de escenas de la telenovela "América" sobre la emigración de brasileños a Estados Unidos, transmitida en el horario de las 21 horas por la Red Globo de Televisión en el año 2005. También fue exhibido un reportaje sobre los migrantes latinoamericanos, transmitido por el Jornal Nacional, también de la Red Globo, como parte de una serie de reportajes sobre la migración contemporánea en Brasil. ${ }^{16}$ En un segundo grupo de discusión fue exhibida una serie de reportajes especiales sobre migraciones, especialmente de latinoamericanos en Porto Alegre, producidas y emitidas en octubre del 2005, en el telediario RBS Noticias. ${ }^{17}$

\section{Caracterización de la muestra de migrantes latinoamericanos}

Del total de 30 migrantes latinoamericanos seleccionados para constituir la muestra de la investigación, 16 son del sexo masculino, y 14 del sexo femenino, nacidos en 11 diferentes países latinoamericanos (tabla 1).

Con relación a las franjas etarias, los entrevistados se sitúan mayoritariamente entre 30 y 49 años, según sintetizamos en la tabla 2.

El nivel de escolaridad de los entrevistados varía entre enseñanza básica completa ( 5 entrevistados) e incompleta ( 1 entrevistado), media completa (6 entrevistados), superior incompleta ( 9 entrevistados) y superior completa ( 9 entrevistados).

El tiempo de permanencia de los entrevistados en Brasil varía entre uno y más de 30 años, conforme se registra en la tabla 3.

Entre las profesiones mencionadas encontramos: acompañante de personas de edad avanzada, cantor, profesor de canto, carpintero, ama de

16 Telediario emitido a las 20 horas que cuenta con la mayor audiencia en el país.

17 Telediario de la principal red de televisión abierta local, la RBS-TV, emitido en el horario de las 19 horas. 
casa, dueño de restaurante, ingeniero mecánico autónomo, esteticista, estudiante, funcionario de pastelería, librero, mecánico gráfico, monitor de proyecto de capacitación digital, profesor de idiomas, profesora universitaria, psicólogo, secretario de consulado y vendedor autónomo.

\section{TABLA 1}

\begin{tabular}{cc} 
País de nacimiento & Total de entrevistados \\
\hline Perú & 6 \\
Argentina & 4 \\
Uruguay & 4 \\
Bolivia & 3 \\
Chile & 3 \\
Cuba & 3 \\
Paraguay & 3 \\
Colombia & 1 \\
Ecuador & 1 \\
Nicaragua & 1 \\
Venezuela $/$ Perú & 1 \\
Total & 30 \\
\hline
\end{tabular}

* El entrevistado nació en Perú, pero es naturalizado venezolano; migró con la familia a Venezuela cuando tenía 10 meses. A pesar de que consideramos el país de nacimiento como criterio para inclusión en la muestra, lo invitamos, inicialmente, por ser naturalizado y haber vivido en este país la mayor parte de su vida.

TABLA 2

Franja de edad Total de entrevistados

$\begin{array}{cc}20 \text { a } 29 \text { años } & 5 \\ 30 \text { a } 39 \text { años } & 9 \\ 40 \text { a } 49 \text { años } & 8 \\ 50 \text { a } 59 \text { años } & 6 \\ 60 \text { a } 69 \text { años } & 1 \\ 70 \text { a } 75 \text { años } & 1 \\ \text { Total } & 30\end{array}$


TABLA 3

Tiempo de permanencia en Brasil Total de entrevistados

\begin{tabular}{cc}
1 a 5 años & 10 \\
6 a 10 años & 3 \\
11 a 15 años & 4 \\
16 a 20 años & 8 \\
21 a 30 años & 3 \\
Más de 30 años & 2 \\
Total & 30 \\
\hline
\end{tabular}

Del universo de los 30 latinoamericanos investigados, 13 ya tuvieron alguna participación en organizaciones de migrantes y en entidades de apoyo a las migraciones, y 15 ya tuvieron presencia o experiencia de intervención en los medios de comunicación de masa y/o alternativos.

Una de las estrategias utilizadas en las entrevistas fue la de solicitar a los propios migrantes que definieran su condición de ciudadanía en Brasil, de modo que fuese posible capturar las dimensiones jurídicoinstitucionales de sus condiciones de permanencia en tal país; las experiencias "vividas" en el cotidiano, así como las percepciones individuales en las cuales lo jurídico-institucional y lo "vivido" se articulan.

Los 15 términos diferentes escogidos por los entrevistados para definir esa condición son reveladores de prácticas y disputas discursivas de naturaleza política, económica, cultural y comunicacional, lo que demuestra la pluralidad de los procesos de ciudadanía de las migraciones contemporáneas: naturalizado, permanencia, visa, permanente regularizado, legalizado permanente, legal, regularización por amnistía, visa permanente por amnistía, permanencia en tramitación, pedido de asilo en tramitación, visa de estudiante, visa de misión religiosa, reasentamiento / refugiado, indocumentado e irregular.

Del total de migrantes de la muestra, 13 afirmaron ya haber tenido participación en organización de apoyo a las migraciones, entre las cuales se destaca el propio CIBAI-Migraciones, y 15 declararon haber participado en medios de comunicación masivos o comunitarios, especialmente como entrevistados en reportajes impresos o audiovisuales sobre las migraciones latinoamericanas. 
MIGRANTES LATINOAMERICANOS, INTERACCIONES MEDIÁTICAS Y CIUDADANÍA ANÁLISIS DE LOS RESULTADOS DE LA INVESTIGACIÓN

\section{Proyectos migratorios en el contexto político}

\section{y económico latinoamericano}

Para algunos entrevistados, el inicio del proyecto de migración está claramente demarcado por episodios de la vida política o económica de sus países, coincidiendo con impulsos de flujos migratorios recientes y relevantes de la historia latinoamericana. Son esos flujos que demarcan dinámicas comunicacionales en torno de las cuales, antes mismo de la formación del MERCOSUR, se instauran relaciones interculturales del sur de Brasil con países latinoamericanos como Argentina, Uruguay, Chile y Paraguay. En los periodos de dictadura en los años setenta y ochenta, Porto Alegre se constituyó en uno de los principales polos de migración de exiliados políticos oriundos de esos países, conforme remiten los recuerdos de uno de los migrantes entrevistados en la investigación.

"Me fueron a buscar, me mandaron a buscar, en la casa donde yo estaba, con una joven, estábamos tomando un trago, conversando, y llegaron los militares. Que, por orden del teniente que yo conozco que ahora él murió así, dijo que era para darme unos tiros, que yo andaba haciendo mucha locura, que era que estaba atacando los militares, estaba tirando bomba, y que era comunista y un montón de cosas, ¿entendió? [...]. Entonces en ese mismo día yo volví para casa y me fui de Chile, y ahí por Argentina, que me dijeron que era para irme enseguida pues la cosa iba ponerse complicada" [...] (Miguel, 51 años, nacido en Chile). ${ }^{18}$

Además de las motivaciones políticas, la decisión por migrar aparece relacionada, en las narrativas de los entrevistados, a crisis económicas cíclicas enfrentadas por países latinoamericanos como Argentina,

18 Los nombres de los entrevistados son ficticios, y las citas literales de las entrevistas están traducidas al español, si bien la mayoría de los entrevistados se expresaron en portuñol. 
Uruguay y Perú. El escenario político y económico de Perú de final de los años ochenta e inicio de los noventa, en el periodo de gobiernos de los presidentes Alan García y Fujimori, es relatado por Vicente, músico de 33 años, como el principal factor que motivó su migración, primero a Argentina, y después a Uruguay y Brasil.

"Bueno, la situación en Perú, económica y social estaba muy destrozada. [...] No teníamos luz, no teníamos agua [...] No podíamos comprar arroz, ni leche, ni nada. Aparte de los atentados terroristas, y que el ejército te tomaba y a la fuerza tenías que ir a la guerra, a pelear con los terroristas. Entonces todas esas situaciones, viendo que no tenía más futuro allí, aparte que yo quería estudiar y la universidad solamente era para la gente que tenía plata. Excesiva corrupción había" (Vicente, 33 años, nacido en Perú).

La crisis económica de Argentina, ligada a los gobiernos de Menem y De La Rua atraviesan igualmente las narrativas relacionadas con las trayectorias de migración de Diego, 43 años, librero y profesor de tango, desde hace 8 años en Brasil, y Claudio, 43 años, ingeniero mecánico autónomo.

“[...] Sólo que sucedió un problema económico muy grave en Argentina, ya estaba el gobierno Menem, él cambió la tendencia política de Argentina, e implantó el neoliberalismo en Argentina [...] Y hundió el país en una decadencia absoluta. Eso fue en la década de 90 [...] Ahí, cuando ya el negocio no daba más, estaba cayendo, el país estaba cayendo en una baja enorme, de movimientos, ahí yo le propuse a mi esposa venir aquí a Brasil. No conseguía sustentar mi familia. Y bueno, volvimos [...]" (Diego, 43 años, nacido en Argentina).

“[...] porque yo, con 55 años, llegó la famosa crisis de los 2001, tenía mi apartamento, mi carro, un buen salario, mi empleo, bueno, un día, reunión, acabó el empleo, la empresa cerró, llegó la crisis, todo el mundo pagando el apartamento en dólares, sólo que el dólar era uno a uno, un dólar, un peso; un día un dólar, cuatro pesos, o sea, de un día para otro la gente quedó sin nada, y con deudas [...] uno de los hijos de mi mujer es brasileño, vive aquí en Brasil, 
dijo que Brasil estaba tranquilo, con posibilidad de trabajo ahí, llegué aquí el 2 de septiembre de 2003, y el 29 de septiembre ya estaba empleado, trabajando como director de obra [...]" (Claudio, 57 años, nacido en Argentina).

Desde esas perspectivas, algunos de los migrantes entrevistados son portadores y (re)creadores de memorias colectivas de la vida política, social y económica latinoamericana contemporánea. No son apenas espectadores mediáticos o narradores de experiencias sociales mediatizadas, sino participantes y testigos de experiencias vividas en episodios preponderantes de las trayectorias sociales e históricas de sus países, experiencias directas de interacción comunicacional que cuestionan o relativizan la noción conceptual de "colonización de la memoria por los medios de comunicación" (Thomson; Frisch; Hamilton, 2006: 90), que se utiliza para enfatizar la creciente penetración de los medios de comunicación en las dinámicas de rememoración de individuos y colectividades en sustitución de sus vivencias y relatos de participación directa en la vida social.

\section{Proyectos migratorios y redes familiares transnacionales}

Muchos de los entrevistados no presentan, por ejemplo, una experiencia única de migración, habiendo circulado o vivido en otros países antes de establecerse en Brasil. En la infancia o juventud ejercitaron la condición de "extranjeros" o "fueron educados" para ser migrantes antes incluso de decidirse por proyectos migratorios individuales. Entre los entrevistados se destacan, también, aquellos que son oriundos de familias que tienen la migración como experiencia fundadora, sea a través de diferentes orígenes y nacionalidades de los padres o por ejercicio del bilingüismo o plurilingüismo en el contexto familiar, sea a través de las experiencias de tránsito vivida por parientes, e, inclusive, por medio de la convivencia con extranjeros posibilitada por la educación familiar.

Las relaciones familiares operan, así, como redes sociales que, desde una perspectiva de las interacciones comunicacionales, dan soporte a los proyectos de migración, en Brasil, en Porto Alegre y en otros espacios de tránsito, de la mayoría de los entrevistados. Conformadas por la relación entre individuos, a consecuencia de co- 
nexiones preexistentes como vecindad, parentesco, amistad, trabajo, clase, etc., las redes sociales son entendidas, desde una perspectiva antropológica y comunicacional, como relaciones semiformalizadas que no responden por la formación sistémica en sí, ya que pueden disolverse o formarse en distintas sociedades (Scherer-Warren, 1999). Con el soporte de las tecnologías de la comunicación, que incluyen desde la carta hasta Internet, las redes contribuyen a la configuración de lo que podemos designar como "relaciones familiares transnacionales", conforme observamos desde las distintas experiencias de los migrantes entrevistados en Porto Alegre.

La presencia del tío en Brasil, interfirió, por ejemplo, en la opción de Víctor de migrar a Porto Alegre y no a otra ciudad brasileña por permitirle contar con un soporte para llevar adelante su proyecto migratorio. El propio tío de Víctor, César, de 51 años, nacido en Perú, cuando migró para Brasil hace 33 años, recuerda que también uno de sus tíos, agrónomo que vive en la ciudad de Curitiba, sur de Brasil, funcionó como conexión para su proyecto migratorio inicial. Los recuerdos de César sobre ese soporte ofrecido por el tío se refieren tanto a las referencias materializadas en recuerdos y postales enviadas a Perú como a la motivación que le dio para intentar la universidad en Brasil.

"Ya te dije que mi tío vino para acá en la década de 60, y siempre nos mandaba cosas sobre Brasil, en mi casa había así varios recuerdos de Brasil que colgábamos en las paredes, siempre intentaba entender lo que decían las postales. Él siempre mandaba postales en portugués. En aquella época no existía toda la diversidad de la Internet, entonces la cosa era más escrita, más leída. Entonces, yo fui criado desde pequeño, mis padres 'tu vas a estudiar en Brasil' y yo 'ah hay una floresta, voy a estudiar en Brasil'[...] Llegó el momento de terminar el colegio y no hubo oportunidad, entonces, bueno [...] . Y mi tío fue para allá (para Perú), ahí yo lo vi. [...] Ahí, ¿¿tú continúas queriendo estudiar en Brasil? Entonces tú vas, haces la selección.' Ahí yo fui, hice la selección, primero en Curitiba. Y sólo que hice la selección y cogí el segundo lugar. Casualmente el muchacho que ocupó mi lugar eligió Curitiba. Entonces yo tenía Rio, São Paulo, Belo Horizonte y Porto Alegre”. (César, 51 años, nacido en Perú). 
Dificultades en el casamiento llevaron a Marta, de 43 años, nacida en Bolivia, a tomar, con las dos hijas, el mismo itinerario migratorio emprendido por la madre hacía 25 años cuando decidió romper con la vida de casada que mantenía en su país y establecerse en Porto Alegre. "Ahí yo hablaba con mi madre, nos escribíamos, y ella decía así: vende todo lo que tú tienes para vender y ven para acá, porque aquí yo cuido de las niñas y tú trabajas, entonces yo fui", relata.

En el caso de algunos de los latinoamericanos, las relaciones afectivas interculturales -como relación afectiva y casamiento con brasileños- también colaboran fuertemente en la decisión de elegir Porto Alegre como lugar de migración y residencia. Después de separarse de su compañera argentina, Octavio se casó con una brasileña que conoció a los 30 anos de edad en una fiesta organizada en un bar que reunía brasileños en Buenos Aires. "Ahí comencé a madurar [...] dos años después vine para Porto Alegre para montar mi gráfica. En lugar de ir para Bahía, vine para Porto Alegre" (Octavio, 43 años, nacido en Argentina).

La facilidad de tránsito, derivada de la proximidad y frontera geográficas de Rio Grande do Sul con países como Uruguay y Argentina, hace que las redes migratorias asuman una perspectiva comunicacional que se relaciona con la implementación de los "proyectos de migración" de muchos entrevistados. El intercambio de imágenes y experiencias entre familiares, amigos y con otros migrantes latinoamericanos que llegan, circulan o se establecen en Porto Alegre u otras ciudades brasileñas son fomentados por una o por las diversas experiencias de retorno y visitas a los países de origen, así como dinamizadas y (re)actualizadas mediáticamente vía procesos de apropiación de medios como Internet.

Producción cultural y mercado mediático: la "latinoamericanidad" como alternativa profesional

La producción cultural, articulada a las apropiaciones de medios de comunicación, constituye uno de los ámbitos privilegiados de construcción de una latinoamericanidad relacionada con las trayectorias migratorias de los entrevistados en Porto Alegre. Es preponderante, entre los migrantes investigados, la incorporación y el ejercicio de actividades profesionales relacionadas con un mercado cultural y mediático que asume como referencia las culturas latinoamericanas o la latinoameri- 
canidad.19 Entre las actividades culturales mencionadas por 10 de los 30 entrevistados, están: música (salsa y andina), danza (salsa y tango), arte, artesanía, producción cinematográfica y bares latinos.

Por esas expresiones culturales, algunos de los entrevistados pasaron a ejercer ese tipo de actividad al establecerse en Porto Alegre, favoreciéndose de una especie de diáspora histórica que sitúa Brasil fuera de América Latina, idea realimentada por cierto extrañamiento cultural con los demás latinoamericanos. Entre los entrevistados eso se evidencia en lo que se refiere al uso del idioma español y en algunas expresiones culturales, como la salsa, no compartida, según sus opiniones, como manifestación cultural por Brasil.

Arturo, 46 años, nacido en Uruguay, dice haber aprendido música informalmente en las calles de Montevideo, especialmente a escuchar y a tocar percusión vinculada al candombe, género de música afroamericana de su preferencia. Cuando llegó a Brasil pasó a dedicarse a la salsa, conforme relata:

"Uruguay es uno de los tantos países que se curte salsa, pero en Brasil no había. Y yo sentía aquella falta, ¿no?, pero como otros extranjeros también comenzaron a formar sus grupitos, a tocar salsa y tal, yo comencé. Sólo que comencé a tocar al lado de gente ya profesional, y esas personas comenzaron a hablar conmigo 'bah, tú tocas bien, tú eres bueno. ¿Por qué no vas a la Orden de los Músicos de Brasil y te haces profesional?'. Ah, yo fui, hice un pequeño curso de solfeo, ta.., hice una prueba, pasé en la prueba, hice el registro de músico y hoy estoy tocando profesionalmente" (Arturo, 46 años, nacido en Uruguay).

Diego, un ex bancario de 43 años, nacido en Argentina, fue copropietario, por 12 años, en sociedad con el hermano, de un bar para bailar música brasileña en Buenos Aires llamado "Uma boa". En Brasil estudió letras, pero las dificultades para costear la universidad le hicieron reorientar el trabajo a dos actividades: la venta de libros y las presentaciones y clases de tango.

19 Si bien esas actividades son ejercidas simultáneamente con otras fuera del área de la producción cultural. 
En el desarrollo de algunas de esas actividades, los entrevistados relataron agregar, además, aprendizajes para el ejercicio de gestión de la producción cultural y de su visibilidad pública en los medios de comunicación en la perspectiva de contornear las limitaciones del mercado de producción cultural de Porto Alegre. Para la divulgación mediática del trabajo de la banda de salsa en que actúa como vocalista, una entrevistada chilena revela haber aprendido estrategias para relacionarse con los medios de comunicación locales y nacionales a través del envío de releases, 20 contactos telefónicos y personales con periodistas y organización de materiales de archivo para enviar a los vehículos de comunicación.

\section{Imaginarios mediáticos:}

\section{Brasil imaginado por los migrantes latinoamericanos}

La música brasileña constituye una de las principales $\mathrm{y}$, muchas veces, la primera experiencia mediática previa a la migración en que un "Brasil visto desde América Latina" es vivenciado por los entrevistados en sus países de origen. Danzar música brasileña, que escuchaban en una emisora de radio en Paraguay, escuchar durante la infancia cantores brasileños en emisoras argentinas, consumir MPB (música popular brasileña) "tipo exportación" en emisoras chilenas o frecuentar un bar brasileño de música en Buenos Aires donde escuchaba y bailaba Maluco Beleza, ${ }^{21}$ son algunos de los recuerdos sobre esas vivencias referidas por los migrantes investigados.

Playa, carnaval, negritud, sexualidad, futbol, telenovela y violencia son mencionados como representaciones transnacionales de un Brasil como nación que configuran lazos y repertorios culturales construidos por los entrevistados en sus países de nacimiento, en gran medida, por el protagonismo de los medios de comunicación.

"La imagen que todo el mundo tiene es samba y carnaval". "Los medios que te demuestran lo que es Brasil samba, folclor, novelas, eso". "Lo que los medios mostraban de Brasil es lógico que primero el car-

20 Textos periodísticos breves enviados a la prensa por asesorías de comunicación para divulgación de eventos.

21 De autoría de Raul Seixas, compositor y cantor brasileño ya fallecido. 
naval y el fútbol [...] playas limpias, fútbol bonito y mujeres fáciles". "Bueno, un país de negros. Inclusive, mis amigos de escuela, cuando querían ofender a un moreno, un negrito, entonces le decían 'brasileño"". "Lo que sucede, la imagen de Brasil fuera de Brasil es muy mala [...] mulata rebolando, turismo sexual en Rio de Janeiro, fútbol, carnaval, y matan los indios". Esos son algunos trozos extraídos de entrevistas donde los migrantes latinoamericanos recuerdan un Brasil que llegaba mediáticamente a sus países a través de la televisión, de la radio y de los periódicos. 22

Esas referencias eran reforzadas por las iniciativas de familiares de algunos entrevistados que, desde Brasil, se encargaban de enviar revistas de historietas brasileñas y postales. También son referidas algunas vivencias escolares sobre historia y geografía obtenidas en los países de nacimiento, conforme recuerda una migrante nacida en Nicaragua, que mencionó haber consumido, desde los cuatro años de edad, literatura infantil brasileña y músicas como chorinho. 23

En los relatos de los entrevistados se percibe el papel que desempeña la industria cultural, especialmente la televisión, en América Latina en cuanto a la integración nacional y unificación de los mercados locales, a ejemplo de lo que sucede en otros contextos internacionales, como observa el antropólogo brasileño Renato Ortiz (1994). Como estrategia de consolidación de las opciones del Estado brasileño por determinados modelos nacionales de modernización y de industrialización para el país, este modelo estuvo representado, en Brasil, sobre todo por los dos grandes centros urbanos de la región sudeste: Rio de Janeiro y São Paulo.

En lo que respecta a la proximidad geográfica y cultural y a los esfuerzos históricos de integración entre los países latinoamericanos, observamos que las experiencias mediatizadas siguen ejerciendo un papel preponderante en la construcción de imaginarios nacionales entre las sociedades y naciones de la región, como resultado, en gran medida,

22 Los trechos de las declaraciones son, en la secuencia, de entrevistados nacidos en Venezuela, Ecuador, Argentina, Perú y Cuba.

23 La entrevistada se refirió al escritor infantil Monteiro Lobato y a los músicos Pixinguinha y Jacob do Bandolim. 
de flujos de información que siguen todavía dependientes, por ejemplo, de las agencias de noticias norteamericanas.

Los viajes de vacaciones y turismo por Brasil o la convivencia con brasileños, antes de partir del país de origen, son experiencias comunicacionales, no mediatizadas, que, referidas por algunos entrevistados argentinos, uruguayos y por un cubano, ayudan a relativizar esas imágenes mediáticas. Pero es, sobre todo, la elección como destino migratorio y la concretización del proyecto de migración para Rio Grande do Sul, uno de los estados más "blancos y europeos" de Brasil, lo que parece colaborar fundamentalmente para pluralizar, en el cotidiano de los entrevistados, esas representaciones unificadas de una nacionalidad brasileña. Algunos entrevistados llegan a expresar recuerdos detallados sobre la sorpresa sentida a su llegada a Porto Alegre al encontrarse con fenotipos alemanes e italianos y con la presencia minoritaria de negros.

"[...] Entonces, fue muy gracioso, como te digo, pensaba que iba a encontrar muchas personas morenas, negras, ¿no?, que iba a ver mucha arara por ahí volando (risas), periquito (risas) entonces ahí fui viendo después que ya no había sólo negrito, pensaba que todas las personas no pasaban de morenas, entiendes, y aquí me deparé con un montón de alemanes (risas), ¿no?, mucho alemán, mucho italiano y tal", (Carmen, 40 años, nacida en Chile).

"Para comenzar yo no sabía que había así una mezcla de razas como la tuya, así blancos así, pensé todo medio moreno, medio negrito. No sabía que habían las colonias italianas, colonias judías, colonias chinas, no tenía ni idea de lo que había acá. Porque mi idea de Brasil es sólo negrito, carnaval, fútbol [...] Allá no se habla mucho de [...] allá en aquella época por lo menos no se hablaba mucho de Brasil, ¿no?” (Miguel, 51 años, nacido en Chile).

"Entonces, mi concepto era así: yo pensaba que Rio de Janeiro sólo gente negra, negra, de color negro, con cabello bien pegadito, y que el resto de la población era de mi color. Pero cuando llegué a Rio Grande, vi así, viajé por todo Rio Grande, conocí muchas ciudades aquí en Rio Grande. Encontraba y bah, parecía que estaba en ciudades de Alemania, o en el interior de Suiza, o sea, cambió bastante mi manera de pensar". (Vicente, 33 años, nacido en Perú). 
Esa experiencia de un Brasil plural puede retornar, inclusive, a los países de origen, experiencia reinterpretada por iniciativa de algunos entrevistados, como la de un migrante cubano que relató llevar a Cuba videos sobre Rio Grande do Sul, para mostrar a amigos aquello que no se acostumbraba ver de la cultura brasileña.

\section{Usos mediáticos y ciudadanía}

de los latinoamericanos en Porto Alegre

Los medios de comunicación operan también como uno de los principales lugares de aprendizaje no formal de la lengua portuguesa durante el proceso de migración, a través del ejercicio de lectura de historietas y de periódicos impresos, así como del consumo de diferentes géneros mediáticos televisivos como telenovela, telediarios y programas de auditorio.

“Televisión, radio, periódico, libros, todo lo que pudiese leer, en aquella época cuando vine, fue muy importante porque sabía muy pocas palabras. Entonces, a través de la televisión, de la radio, del periódico, de libros, fui asimilando el idioma" (Arturo, 46 años, nacido en Uruguay).

"Lenguaje es la diferencia. Muchas palabras, sonidos iguales, pero significados diferentes, no se entiende. Y el lenguaje, cuando llegué aquí no hablaba nada, no entendían lo que hablaban y nadie entendía lo que yo hablaba. Yo no era fluido, fui escuchando, por ejemplo, televisión, tratando de leer periódicos", [...] (Fernando, 43 años, nacido en Cuba).

Sobre el acceso y consumo de medios de comunicación en Brasil, algunos entrevistados destacan los contrastes en los padrones de producción de medios de comunicación brasileños, especialmente de la televisión (ritmo, estética, modalidades de programación) con relación a sus países de origen. Eso evidencia la heterogeneidad en la estructuración de las industrias culturales y en las culturas mediáticas entre las distintas naciones latinoamericanas, así como las diferentes temporalidades en la apropiación y usos de los medios y tecnologías de la comunicación por parte de los entrevistados como resultado de esa estructuración y, al mismo tiempo, las condiciones desiguales de acceso de medios en su país de origen y en Brasil. 
En las historias mediáticas de los latinoamericanos entrevistados, la heterogeneidad en el acceso a los medios aparece, por ejemplo, en el relato sobre la presencia central de la radio en algunas trayectorias, incluso más que la televisión. También aparece, en relatos de dos entrevistadas de Bolivia, el recuerdo de la llegada tardía de la TV por falta de luz eléctrica, así como la necesidad de dividir el aparato de televisión con vecinos. El uso de carta convencional concomitante al correo electrónico para comunicarse con el país de origen es relatado por una entrevistada cubana y una boliviana, en contraste con el relato sobre el acceso a la TV por cable e Internet antes de la migración, hace más de 10 años, por un migrante procedente de Lima, Perú.

En Porto Alegre, el consumo de medios como Internet se reordena, en el cotidiano de los entrevistados, por exigencia de los propios itinerarios migratorios que motivan aprendizajes para el uso de recursos como correo electrónico y chat en la comunicación con familiares y amigos, o para la lectura de las versiones online de la prensa de los países de origen. Aprendizajes de uso de Internet en bibliotecas públicas, en universidades, favorecidas por el intercambio y auxilios, más o menos individuales, en los lugares de trabajo o en la iglesia son algunas de las iniciativas relatadas por los entrevistados para potenciar el acceso a la Internet en Porto Alegre. Acceso que es condicionado, según ellos, por el alto costo del uso privado de la red y, principalmente, por las limitaciones de locales públicos, como cybercafés o locutorios que permitan ese acceso. Lo que entendemos por competencias mediáticas para el uso de los medios de comunicación son desarrolladas también por los latinoamericanos investigados en el ámbito del consumo y en algunas experiencias de participación, como entrevistados en medios masivos y alternativos a partir de la agenda de temas relacionados con la migración latinoamericana. ${ }^{24}$ Vale registrar, con relación a eso, el expresivo uso del teléfono celular y del correo electrónico en la dinámica del contacto y la agenda de las propias entrevistas con migrantes durante la realización del trabajo de campo.

24 Mitad de los entrevistados mencionó alguna experiencia de participación en medios. 
Interacciones comunicacionales y ciudadanía en las redes migratorias Observamos que la propia constitución diversa de las culturas latinoamericanas posibilita múltiples autorrepresentaciones, identificaciones y negociaciones de identidad en los procesos migratorios de los latinoamericanos entrevistados en Porto Alegre. Lo que acaba potenciando, también, vivencias de ciudadanía que no asumen únicamente un carácter objetivo, regulador e institucional, y que aparecen traspasadas por experiencias subjetivas relacionadas con lo que Mezzadra (2005) define como movimiento y acción, y que se desarrollan en torno a demandas de integración socioculturales de las migraciones muchas veces parciales, fragmentadas y ambivalentes.

En la perspectiva de las redes sociales y de la ciudadanía, las migraciones transnacionales oriundas de países de América Latina se dinamizan, en Porto Alegre, en torno a interacciones comunicacionales y mediáticas que asumen un carácter comunitario y asociativo. A través de las fiestas, celebraciones y otros eventos de carácter religioso, cultural y gastronómico que buscan congregar migrantes latinoamericanos de diferentes nacionalidades, las redes sociales de los migrantes asumen una perspectiva colectiva al constituirse como un espacio de interacciones informales de una pluralidad de individuos, grupos y/o organizaciones que, movidos por causas políticas y/o culturales, se congregan alrededor de una identidad colectiva común (Scherer-Warren, 1999).

En el caso de los migrantes latinoamericanos estudiados, las iniciativas de las redes y organizaciones de migrantes combinan la reafirmación de la pertenencia a una nacionalidad con la búsqueda de construcción de experiencias políticas y de identidades comunes en torno a la latinoamericanidad. Es lo que pudimos observar en los casos específicos de los migrantes peruanos y de la organización de apoyo a los migrantes, como el CIBAI-Migraciones. Los migrantes peruanos se destacan por encuentros culturales-gastronómicos realizados periódicamente y que, a través de procesos de divulgación que cuentan con el auxilio de las propias redes migratorias y de tecnologías de comunicación con Internet, acaban funcionando como espacio de congregación de migrantes de diferentes nacionalidades.

En lo que se refiere al CIBAI-Migraciones, esas iniciativas en el ámbito cultural se asocian a otros proyectos de apoyo material (para 
residencia, trabajo, por ejemplo) y asesoramiento jurídico que involucra la perspectiva de la integración sociocultural y ciudadana de los migrantes latinoamericanos en Porto Alegre. Además, experiencias de participación mediática de los migrantes son articuladas a partir del CIBAI-Migraciones a través del papel que la entidad desempeña en la formulación de políticas mediáticas para visibilidad de las migraciones transnacionales de latinoamericanos en el ámbito local. 25

Un ejemplo fue la serie de reportajes sobre las migraciones latinoamericanas en Porto Alegre exhibida por una de las principales redes regionales del sur de Brasil (la RBS-TV). La producción del material periodístico fue realizada a partir del contacto de los periodistas con el equipo de la entidad, tanto en lo que se refiere a la elección y focalización del tema, como a la intervención en el proceso productivo del programa a través de la indicación de dirigentes de la propia entidad o de migrantes latinos, algunos en situación de clandestinidad, para ser entrevistados.

Es posible percibir, sobre todo, la incidencia, tanto en el producto final (el reportaje) como en la visión sobre las migraciones que obtuvimos en entrevista con la reportera y productora, de dos perspectivas que vienen orientando esa articulación entre CIBAI-Migraciones y migrantes latinoamericanos, en favor de un tipo de visibilidad pública y mediática de las migraciones transnacionales, especialmente oriundas de países de América Latina, en el ámbito local y nacional: 1) el énfasis en aspectos relacionados con lo cotidiano y la cultura de los migrantes latinoamericanos a través de la visibilidad dada a sus historias de vida, trayectorias de migración y expresiones culturales y religiosas, y 2) la evidencia de demandas, institucionales y no institucionales, ligadas a la ciudadanía comunitaria y cosmopolita, especialmente aquellas relacionadas con la condición de clandestinidad de las migraciones contemporáneas y con la libertad de circulación de los migrantes más allá de las circunscripciones nacionales y jurídicas.

Esas dos perspectivas pueden ser observadas no sólo en las relaciones del CIBAI-Migraciones con los medios locales a través del envío de pautas y otros tipos de informaciones, sino igualmente a través de

25 El CIBAI-Migraciones actúa en articulación con otras organizaciones similares nacionales e internacionales. 
iniciativas de comunicación comunitaria por parte de la entidad, como la de la edición del boletín impreso Familia da Pompéia, publicación trilingüe (portugués, español e italiano) dirigida a migrantes latinoamericanos y de otras nacionalidades, así como la del desarrollo de otros materiales impresos y audiovisuales, como el video "Rostros".

\section{CONSIDERACIONES FINALES}

Este itinerario de análisis contribuye a una reflexión final en torno a tres cuestiones centrales que pautan las relaciones entre medios de comunicación y perspectiva transnacional de las migraciones latinoamericanas en el mundo contemporáneo, y que observamos reafirmadas en el contexto local de la investigación. La primera se refiere a una visibilidad pública de esas migraciones que colabore con la construcción de una memoria plural sobre las culturas migratorias en Brasil, especialmente en lo que refiere a la visibilidad e inclusión ciudadana de las culturas latinoamericanas en el escenario social contemporáneo del país. Vale mencionar que, en una investigación realizada anteriormente, constatamos cuánto el imaginario construido por los medios de comunicación sigue privilegiando y (re)actualizando el legado cultural de migrantes europeos, especialmente alemanes e italianos, que colonizaron Brasil en siglos pasados (Cogo, 2006).

La segunda perspectiva apunta a la creación de estrategias de usos de los medios de comunicación en los procesos de ciudadanía de los migrantes latinoamericanos en Porto Alegre. Vivida de modo heterogéneo y no sólo desde una perspectiva jurídica, la ciudadanía es producida cotidianamente por los migrantes en interacciones comunicacionales y mediáticas que colaboran con la construcción, en ámbito local, de las migraciones como experiencias transnacionales.

Una tercera y última perspectiva refiere a las migraciones como lugar transnacional de (re)actualización de la latinoamericanidad como una construcción identitaria y ciudadana plural. Modos de ser y sentirse latinoamericano desde Porto Alegre, pero relacionados con Rio Grande do Sul, con todo Brasil, con América Latina, con los países de nacimiento y con otros espacios culturales de tránsito y/o vinculación cultural se reafirman, entre los migrantes latinoamerica- 
nos, como una "tarea inconclusa" (García-Canclini, 2002) de esfuerzo de combinación y (re)invención permanente de modos específicos de usos de los medios de comunicación, así como de interacciones comunicacionales individuales y colectivas que no dependen exclusivamente de una materialidad mediática.

\section{Bibliografía}

ANDERSON, Benedict (1997) Comunidades imaginadas - reflexiones sobre el origen y la difusión del nacionalismo. México: Fondo de Cultura Económica.

AvILA, Carlos Federico Dominguez (2007) “O Brasil diante da dinâmica migratória intra-regional vigente na América Latina e Caribe: tendências, perspectivas e oportunidades em uma nova era". Revista Brasileira de Política Internacional. jul./dic. 2007, vol. 50, núm. 2, pp. 118-128.

BERTAUX, Daniel (2005) Los relatos de vida-perspectiva etnosociológica. Barcelona: Ediciones Bellaterra.

Cogo, Denise, Gutiérrez, María, Huertas Bailén, Amparo (2008) Medios de comunicación y migraciones transnacionales: relatos desde Barcelona e Porto Alegre, Madrid: Los Libros de la Catarata.

- (2006) Mídia, interculturalidade e migrações contemporâneas. Rio de Janeiro/Brasília. E-Papers/CSEM.

CORTINA, Adela (2005) Cidadãos do mundo: para uma teoria da cidadania, São Paulo: Loyola.

GARCÍA Canclini, Néstor (2002) Latinoamericanos buscando lugar en este siglo. Buenos Aires: Paidós.

- (1996) Culturas híbridas. Estrategias para entrar y salir de la modernidad. Mexico: Grijalbo.

GARCÍA Ferrando, Manuel.; Ibáañez, Jesús.; Alvira, F. (1996) El análisis de la realidad social: métodos y tecnicas de investigación. Madrid, Alianza Editorial.

GRIMSON, Alejandro (1999) Relatos de la diferencia y la igualdad: Los bolivianos en Buenos Aires. Buenos Aires: Eudeba/FELAFACS.

GIROLA, Lidia (2007) "Modernización, modernidad y después. Las ciencias sociales en América Latina y la construcción de los imaginarios de la modernidad", en Girola, Lidia y Olvera, Margarita 
(coords.) Modernidades - narrativas, mitos e imaginarios. Barcelona/México: Anthropos/UAM-Azcapotzalco.

HUERTAS Bailén, Amparo (2002) La audiencia investigada. Barcelona: Gedisa.

MARTín-Barbero, Jesús (1987) De los medios a las mediaciones. Mexico: Gustavo Gilli.

MATA, María Cristina (2006) "Comunicación y ciudadanía: problemas teórico-políticos de su articulación", en Fronteiras - estudos midiáticos. vol. 8, núm. 1, pp. 5-15. São Leopoldo:Unisinos.

MEZZADRA, Sandro (2005) Derecho de fuga: migraciones, ciudadanía y globalización. Madrid: Traficantes de Sueños.

OROZCO Gómez, Guillermo (1993) “Dialéctica de la mediación televisiva - estructuración de estrategias de recepción por los televidentes", en Anàlisi. Barcelona, núm. 15, pp. 31-44.

ORTIZ, Renato (1994) A moderna tradição brasileira. $5^{\mathrm{a}}$ ed. São Paulo: Brasiliense.

SCHERER-Warren, Ilse (1999) Cidadania sem fronteiras: ações coletivas na era da globalização. São Paulo: Hucitec.

TAYLOR, Charles (2006). Imaginarios sociales modernos. Barcelona, Paidós.

ThOMsOn, A.; Frisch, M.; Hamilton, P. (2006) "Os debates sobre memória e história: alguns aspectos internacionais", en Ferreira, M. M.; Amado, J. (orgs.), en Usos \& abusos da história oral. $8^{\mathrm{a}}$ edição. Rio de Janeiro: Ed. FGV.

URIBE, Ana (2004) "Receptores nómadas: confluencias entre recepción televisiva y migración trasnacional”, en Intexto. Porto Alegre. v. 2, n. 11. Disponible en: http://www.intexto.ufrgs.br/. Acceso en: 16/02/2007.

ZAMBERLAM, Jurandir (2004) O processo migratório no Brasil e os desafios da mobilidade humana na globalização. Porto Alegre: Palotti. 